\title{
Review of DC-AC converters for photovoltaic conversion chains
}

\author{
Mounir Bouzguenda ${ }^{1}$, Tarek Selmi ${ }^{2}$ \\ ${ }^{1}$ Department of Electrial Engineering, College of Engineering, King Faisal University, Saudi Arabia \\ ${ }^{2}$ University of Tunis El-Manar, Faculty of Mathematical, Physical and Natural Sciences of Tunis, Laboratory of Analysis \\ and Processing of Signals, Electrical and Energy Systems, Tunisia
}

\begin{tabular}{|c|c|}
\hline Article Info & ABSTRACT \\
\hline Article history: & \multirow{12}{*}{$\begin{array}{l}\text { This paper is devoted to the state of the art in photovoltaic (PV) conversion } \\
\text { chains and their architectures. Two major characteristics are considered to } \\
\text { classify these chains. These are the galvanic isolation and the number of } \\
\text { stages; characteristics generally localized around the DC-AC converter } \\
\text { (inverter) at the end of the PV conversion chain. Therefore, this paper deals } \\
\text { with a comprehensive review of the different inverter topologies that can be } \\
\text { integrated into PV conversion chains, distinguishing between the transformer } \\
\text { based and the transformer-less conversion chains. The paper demonstrates } \\
\text { that to this date, transformer-based inverters are very common and widely } \\
\text { used, have a long record of accomplishment as a component of solar energy } \\
\text { systems, in particular for residential applications because of their greater } \\
\text { efficiency, smaller size, and lower costs. Nevertheless, transformer-less } \\
\text { chains are touted with some problems and shortcomings. Moreover, solar } \\
\text { energy storage devices, wireless charging systems in stations and along the } \\
\text { highways require the re-examination of the existing solar PV conversion } \\
\text { chains, their architectures and possibly new conversion chains suitable for all } \\
\text { distributed generation including electric cars and storage devices. }\end{array}$} \\
\hline Received Jul 6, 2020 & \\
\hline Revised Jan 11, 2021 & \\
\hline Accepted Feb 22, 2021 & \\
\hline Keywords: & \\
\hline Conversion chains & \\
\hline DC-AC inverter & \\
\hline Galvanic isolation & \\
\hline & \\
\hline & \\
\hline & \\
\hline & \\
\hline
\end{tabular}

This is an open access article under the CC BY-SA license.

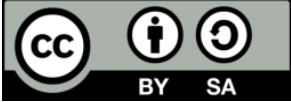

Corresponding Author:

Mounir Bouzguenda

Department of Electrial Engineering

College of Engineering, King Faisal University

P.O. Box 380, Al Ahsa PC 31982, Kingdom of Saudi Arabia

Email: mbuzganda@kfu.edu.sa

\section{INTRODUCTION}

Solar radiation is the largest flow of energy entering the earth system. After reflection and absorption in the atmosphere, much of it can be converted into various forms of energy used by mankind. Nowadays, according to [1], the actual power of the PV system is less than 60-75\% of the estimated electricity production. The ALCEN Corporate Foundation for Energy Knowledge [2] reported that this energy corresponds to nearly 6,000 times the energy consumed by the entire world population. As a result, solar energy has the potential to develop into a major component of the sustainable energy family. This renewable energy was used by ancient civilizations for heating water, desalination, and food drying.

a. Since the nineteenth century, solar energy has been the scope of a growing number of research projects and developments. Key and developments are the discovery of the photovoltaic effect by Bequerel in 1839 [3].

b. Discovery of the photoconductivity of selenium by Willoughby Smith in 1873 .

c. The development of the first working solar cell by Charles Fritts with a 1 percent efficiency in 1883. 
d. The development of the first solar cell with an efficiency of 6 percent in 1954. This was followed by the development of solar cell with an 8 percent in 1957, 14 percent in 1960, 32.3 percent in 1999 and 42.8 percent in 2007.

e. Solar cells cost dropped from \$76 in 1977 to \$0.25 per Watt in 2017.

f. DC to AC inverter is as important as the solar panels and they at the heart of domestic solar power systems, converting the DC to AC. Inverters have been experiencing continued development since late nineteenth century. In 2000 Sandia Laboratories invented the modern inverter paving the way to residential solar systems deployment

g. Apart from the above developments, the widespread smart grids have been dictating additional requirements on solar PV inverters such as autonomy, adaptivity, cooperation, plug-and-play functions, communication, and self-awareness [4]. Such requirements are expected to affect the inverter topology and physical properties. However, these additional requirements can be addressed in a separate study.

h. However, the global production of photovoltaic energy has so far remained low compared to the potential of this resource. This is mainly due to the high production cost of this energy, which is still dominated by that of fossil energy. As a result, the main challenge is finding low-cost and high-efficiency solutions for developing new photovoltaic power systems.

i. Improving the efficiency of the photovoltaic generator by integrating new cell technologies such as organic cells or light-concentration cells.

j. Improving the efficiency and cost of the entire system by setting up new architectures of photovoltaic conversion chains.

Given the fact that the global market for solar PV grew about 44\% in 2019 [5], the fact that the global total of $627 \mathrm{GW}$ including on- and off-grid systems [5] and the fact that the solar solar efficiency has been witnessing marginal improving, other alternatives should be investigated to maximize the power from solar photovoltaic systems. In particular and it is without doubt that the architecture of the DC-AC conversion chains shall be evaluated, and it is in this context that comes the work developed in this paper.

\section{PHOTOVOLTAIC CONVERSION CHAIN ARCHITECTURE}

A solar photovoltaic conversion chain consists of several subsystems [6] that provide various functionalities as illustrated in Figure 1. Such functions include production, conversion, and interface. These functions are common in all photovoltaic conversion chains. Auxiliary functions include control, protection, and storage and differ from one chain to another. Grid connected conversion chains do not require storage batteries as the conversion chain is fed directly from the solar panels and produce alternating voltage and supports the customer load.

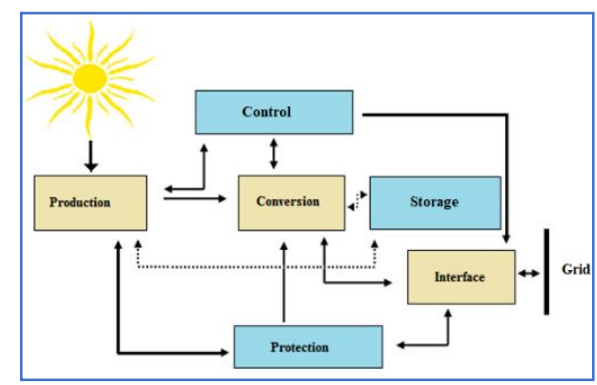

Figure 1. General architecture of solar photovoltaic conversion chains

Solar PV chains can be classified by different families according to the number of power processing stages, the use and of a transformer and otherwise the elimination a transformer.

a. The galvanic isolation between the source and the grid consists of an isolation transformer designed at high frequencies (HF) on the source side via a high frequency of $1 \mathrm{kHz}$ or higher. Alternatively, a transformer is placed on the grid side and operates at a low frequency (LF) of 50 to $60 \mathrm{~Hz}$.

b. The number of stages in the chain. In one hand, the conversion of the energy is achieved straight from direct current $(\mathrm{DC})$ the alternating current $(\mathrm{AC})$. Otherwise, the conversion is done through a buck-boost DC-DC stage to regulate the DC voltage before the DC to AC conversion.

c. Additionally, solar photovoltaic chains architecture is characterized by constraints such as efficiency improvement, the input power fluctuations reduction, production optimization during irradiation 
intermittency and the reliability improvement and extension of the lifetime of key components such as the electrolytic capacitors, inductors, etc.

As a result, various topologies of photovoltaic conversion chains have been developed and reported in the literature. In the following, a special focus will be given to the topologies that have caught the attention of most researchers in the field of photovoltaic systems. This study focuses on the essential function of any chain which is the "conversion" function as well as the auxiliary functions such as protection, connection with the grid and others.

\subsection{Galvanic conversion lines of high frequency type}

Galvanic isolation is ensured by means of a compact HF transformer. However, the transformer exhibits extra losses penalizing therefore the efficiency of the conversion chain [7]-[10]. The diagram in Figure 2 shows the galvanic isolation principle. This type of isolation is based on the flyback approach that uses high value capacitors at the input stage. This approach tends to significantly reduce the entire conversion chain lifetime.

The input voltage, generally of the order of $12 \mathrm{~V}$, is converted into very high AC voltage (HF pulses of the order of $400 \mathrm{~V}$ ). This voltage is rectified and filtered to provide a high DC voltage that is applied to the input of the inverter to produce "consumable" AC voltages. The use of HF galvanic isolation applies to systems having few PV modules in series producing few hundred Watts. The current waveforms are quasisinusoidal due to the adopted control strategies.

\subsection{Conversion chains with low-frequency galvanic isolation}

The schematic diagram of such chains is shown in Figure 3. In this case, the DC input voltage is converted into $\mathrm{AC}$ voltage through the inverter. The LF transformer amplifies this voltage to standard values $(110 / 220 \mathrm{~V}, 50-60 \mathrm{~Hz})$. This type of isolation is the least used because of their relatively high prices, weight and size compared to conversion with HF transformers [7]-[10].

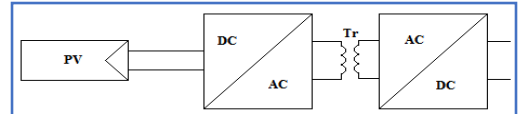

Figure 2. Galvanic isolation using HF transformer

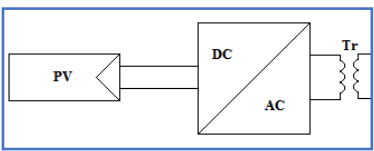

Figure 3. Galvanic isolation using LF transformer

\subsection{Non-isolated conversion chains}

In this galvanic isolation chains, the non-isolated dc-dc converters are designed to step-up or stepdown the voltage. As a result, the size, the weight and the volume of the chains.are compact and the conversion efficiency is enhanced.

\subsubsection{Non-isolated mono-stage conversion chains}

In this case, the conversion is done in a single step without a voltage amplification stage. As shown in Figure 4, many photovoltaic modules are required to generate a voltage at the output of the inverter that is sufficiently high, close to that of the grid. The additional functions (MPPT and protection) are all integrated in a single stage of the conversion chain.

\subsubsection{Non-isolated two-stage conversion chains}

In this case of photovoltaic systems, the conversion chain consists of two cascaded stages. The first stage is a DC-DC converter to boost the DC voltage generated by the photovoltaic panel while the second stage is DC-AC type, allowing the generation of an AC voltage to interface the photovoltaic system with the grid as shown in Figure 5. In this case, the additional functions could be distributed between the DC-DC converter and the DC-AC converter.

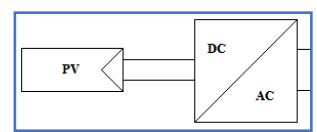

Figure 4. Non-isolated single-stage structure

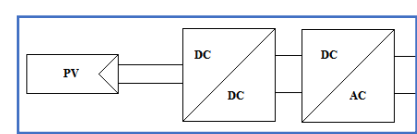

Figure 5. Non-isolated two-stages structure 


\section{CONFIGURATIONS OF PHOTOVOLTAIC CONVERSION CHAINS}

This section reviews the various configurations of the photovoltaic conversion chains according to their DC-to-AC conversion stage.

\subsection{Photovoltaic conversion chains based on central inverters}

The central inverter configuration system is shown in Figure 6 [11]-[15]. It is frequently used for high power applications. In this type of configuration, photovoltaic modules are mounted in rows with each end of a non-return diode. The rows are connected in parallel to the input of the central inverter. It is a simple configuration characterized by low installation and maintenance cost. However, the central inverter chain is penalized by losses due to the phenomenon of asymmetry, also known as mismatch phenomenon, which is linked to the use of a single MPPT strategy implanted in the said inverter. In addition, in case the inverter is faulty, the entire conversion chain is isolated, and no continuity of service is possible. Moreover, the use of long cables connecting the photovoltaic modules compromises the efficiency of the conversion chain.

\subsection{Photovoltaic conversion chains based on string inverters}

Nowadays, as per the "system technology for photovoltaics" [16], the string inverter configuration the most used system configuration. The schematic diagram of this configuration is given in Figure 7 [17], [18]. It involves connecting an inverter to each row of photovoltaic modules and paralleling the outputs of the different inverters.

The inverters need certain synchronization to avoid any exchange of power. Each inverter has its own MPPT which allows better control of the power. In addition, in case of failure of an inverter, only the row associated with it is isolated which allows continuity of service. Finally, such an arrangement offers a modularity that allows an easy chain extension.

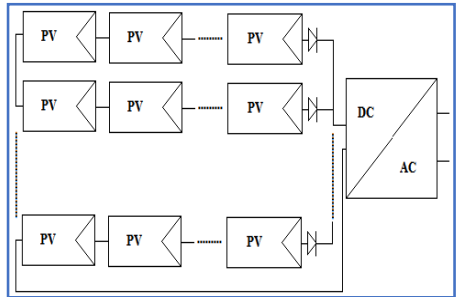

Figure 6. Block diagram of the central inverter system configuration

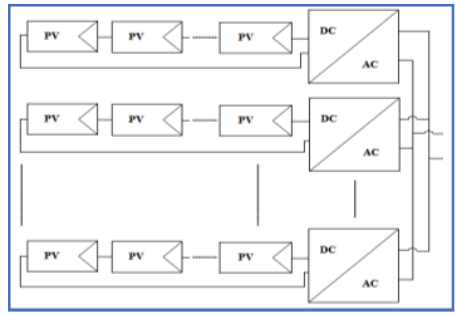

Figure 7. String inverter system configuration

\subsection{Multistring system configuration}

The efficiency and reliability of the conversion chain could be improved by connecting the DC-DC converter to each row or string [19], [20]. The converters' outputs are connected in parallel to the input of a central inverter as shown in Figure 8. This configuration combines the advantages of the central inverter configuration with those of the string inverter configuration. Indeed, the maximum power point trackers (MPPT) are integrated at the converter level, which makes it possible to overcome the losses due to the phenomenon of mismatch. This configuration is certainly more economical than the string configuration but cannot ensure the continuity of the service offered by the latter in case of failure of the central inverter.

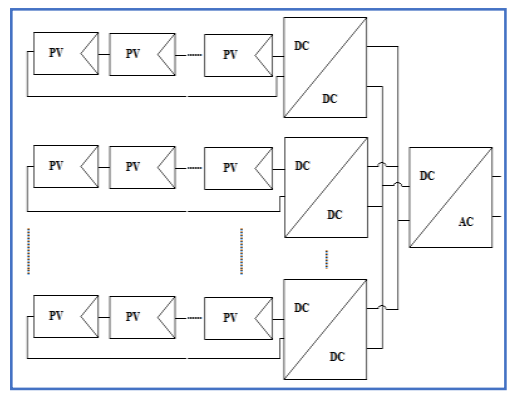

Figure 8. Multi-string inverter conversion chain 


\subsection{Integrated system configuration}

This category includes the following three configurations, namely [21]-[23], i) parallel converter configuration, ii) series converter configuration, and iii) microinverter configuration. The three configurations listed above are respectively shown in Figure 9, Figure 10 and Figure 11. As shown in Figure 9, each of the parallel or the parallel converter configuration shown in Figure 9, each converter is connected to a photovoltaic module having its own MPPT which improves the power generation management. In addition, this configuration allows a more precise control system and a quick response in the event of a fault.

However, this configuration requires high amplification gain of the voltage to match the required voltage at the input of the inverter, which significantly increases the losses and thus penalizes the efficiency of the entire conversion chain.

To reduce this gain, series converter configuration shown in Figure 10 is recommended. Indeed, this configuration allows access to the parallel converter configuration options except that the gain of amplification is reduced as the number of converters increases. The drawback of this configuration lies in connecting several converters which results in the dependence of the MPPT of different converters.

Another configuration considered in the literature is the microinverter system design shown in Figure 11. This configuration consists in connecting the inverter directly to the photovoltaic module via a voltage amplification stage. This design would reduce losses due to the mismatch phenomenon and would allow flexible extension through the "plug and play" technique.

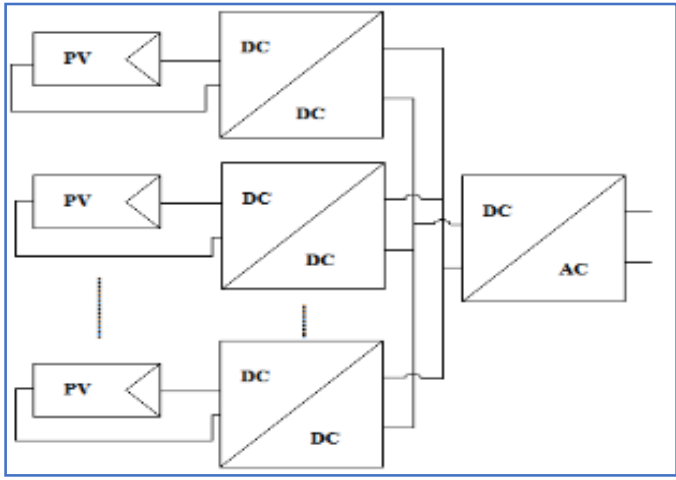

Figure 9. Parallel converter configuration

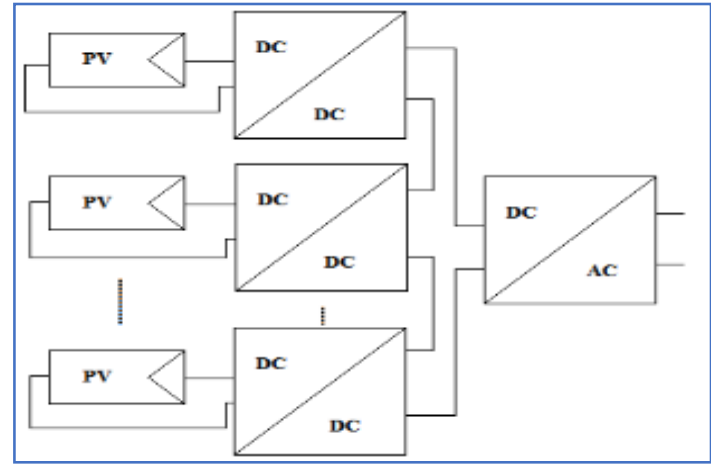

Figure 10. Series converter configuration

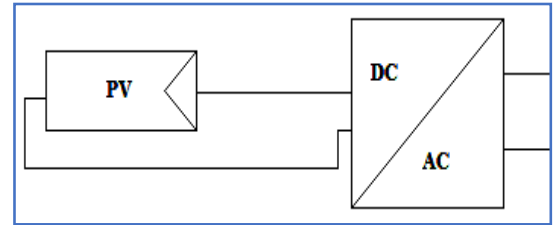

Figure 11. Microinverter system configuration

\section{INVERTER TOPOLOGIES OF PHOTOVOLTAIC CONVERSION CHAINS}

\subsection{Categories of inverters}

The inverter is the major element of any photovoltaic conversion chain. Inverters could be classified into two categories, namely:

a. "Line-switched" inverters which are usually of high powers. They are made of thyristors whose switching frequency is controlled from the line current. However, the thyristor requires forced switching circuits to bring the current to zero to turn them OFF. In addition, inverters made up of thyristors require complicated filtering circuits. For these reasons, this type of inverter is rarely used as reported in the [24].

b. "Self-commutated" inverters that are based on power transistors such as bipolar transistors, field effect transistors (MOSFETs) and insulated gate bipolar transistors (IGBTs). Those inverters are controlled using simple switching techniques implemented in analog or digital integrated circuits [25]. They could 
be voltage controlled called "voltage source inverter" (VSI), or current controlled called "current source inverter" (CSI).

c. VSI inverters are the most used because a high-power factor could be achieved by a simple pulse width modulation (PWM).

d. The use of CSI inverters is generally limited to medium and high-power applications. CSIs have a series of inductors at the DC bus to maintain constant current. These inverters have the following advantages [26], i) in the event of a short-circuit, the current remains limited within the inverter which, thanks to the inductances of the DC bus, cannot exceed the short-circuit current of the PV panel, and ii) the use of sensors is not necessary because the connection of the inverter to the grid does not use any control loop.

\subsection{Inverter specifications}

For all inverters categories, there are technical specifications that must be taken into consideration when developing a PV conversion system. Among these specifications, the total harmonic distortion (THD) and power factor $(\mathrm{PF})$ are retained [27].

The "929-1988-IEEE Recommended Practice for Utility Interface of Residential and Intermediate Photovoltaic (PV) Systems (1987)" [28] has stated that the total harmonic distortion is defined as the ratio of the square root of the sum of the squares of the rms values of the analyzed signal to the rms value of its fundamental term. This value is always given in percent as indicated in (1).

$$
T H D(\%)=100 \frac{\sqrt{\sum_{n=2}^{\infty} H_{n}^{2}}}{H_{1}}
$$

where $\mathrm{H}_{n}$ is the rms value of the nth harmonic and $\mathrm{H}_{1}$ is the rms value of the fundamental term. According to US IEEE P929 [28], the THD of the currents must always be less than 5\%. Table I shows the THD limits adopted by most standards [29].

Table 1. THD limit of the current according to the order of the harmonics

\begin{tabular}{cc}
\hline Order of harmonics & Limit of the THD \\
\hline $2-9$ & $4 \%$ \\
$10-15$ & $2 \%$ \\
$16-21$ & $1.5 \%$ \\
$22-33$ & $0.6 \%$ \\
THD up to the $50^{\text {th }}$ harmonic & $5 \%$ \\
\hline
\end{tabular}

The second specification is the power factor which is of dominant importance. A unit power factor is often required where it is associated with low values of current. This results in a reduction of losses within the chain and consequently a better profitability of the photovoltaic conversion.

The effective value of the current is expressed as (2).

$$
I_{r m s}=\sqrt{\sum_{n=1}^{\infty} I_{n}^{2}}
$$

Where $I_{n}$ is the amplitude of the harmonic of order $n$.

Similarly, the rms value of current could be expressed as a function of THD as (3).

$$
I_{r m s}=I_{1} \sqrt{1+T H D^{2}}
$$

In addition, the power factor PF is described in the "1547.1-2005 - IEEE Standard Conformance Test Procedures for Equipment Interconnecting Distributed Resources with Electric Power Systems (2011)" [30], [31] as (4).

$$
P F=\frac{P}{S}=\frac{I_{1} \cos \phi}{I_{r m s}}
$$

with $\varphi$ is the back-phase shift of the current fundamental term with respect to the fundamental term of the voltage.

Rewriting (4) while considering (3), makes it possible to express the power factor as a function of the THD as shown in (5). 


$$
P F=\frac{\cos \phi}{\sqrt{1+T H D^{2}}}
$$

In addition to the two specifications described above, any photovoltaic system is characterized by further specifications related to security and coupling to the grid. These specifications are dictated by the following standards, a) IEC 60364-7-2005: Electrical installations of buildings section 712: photovoltaic power systems (2016) [30], b) IEEE 1547-1-2005: Standard IEEE conformance test procedures for equipment connecting distributed sources to electrical grids (2011) [29], c) IEEE 929-2000: Practical interfacing of photovoltaic systems (2000) [32], d)IEC 61727: Photovoltaic systems: characteristics of the interface (2004) [33], and e) DS / EN 61000-3-2: EMC, limits for harmonic emissions (Input current of equipment that can wait 16A per phase) (2019) [34].

Table 2 shows a comparison of forth mentioned standards in terms of current injected into the grid. The VDE 0126-1-1 standard is the only one that imposes a disconnection time from the grid in the order of $200 \mathrm{~ms}$ if a direct current greater than 1A is injected into the grid [35]-[37]. This standard also requires the disconnection of the conversion system if a leakage current occurs, as shown in Table 3 [38]. Considering the technical specifications of photovoltaic systems, several inverter topologies that more closely meet these specifications have been studied and are presented within this paper that mainly focuses on, a) inverters with galvanic isolation, and b) inverters without galvanic isolation.

Table 2. Injected direct current limit for different

\begin{tabular}{ll} 
& \multicolumn{1}{c}{ standards } \\
\hline \multicolumn{1}{c}{ Standard } & \multicolumn{1}{c}{ DC injected } \\
\hline IEC 61727 & $\leq 1 \%$ of the output current \\
VDE $0126-1-1$ & $\leq 1 \mathrm{~A}$ \\
IEEE 1547 & $\leq 0.5 \%$ of the output current \\
EN $61000-3-2$ & $\leq 0.22 \mathrm{~A}$ \\
IEEE $929-2000$ & $\leq 0.5 \%$ of the output current \\
\hline
\end{tabular}

Table 3. Maximum disconnection time according to VDE 0126-1-1

\begin{tabular}{cc}
\hline Leakage current $(\mathrm{mA})$ & Disconnection time (s) \\
\hline 30 & 0.30 \\
60 & 0.15 \\
100 & 0.04 \\
\hline
\end{tabular}

\subsection{Flyback mono-transistor inverter}

The schematic diagram of this topology is shown in Figure 12. This is a galvanically isolated topology using a high frequency (HF) transformer. It is a low power inverter (around 100W) based on a single-transistor flyback converter whose outputs feed a mid-point transformer [39]-[42]. Both outputs of the transformer are connected to the grid through two diodes, two transistors and a filter. This configuration allows the Flyback converter to provide two currents of opposite signs. The two output transistors synchronously switch with the single transistor of the flyback converter in the high frequency regime. The Flyback converter operates in a discontinuous conduction mode (DCM) which implies that the current through the transformer reaches zero before the start of each switching cycle.

The major disadvantage of this topology lies in the fact that the decoupling of the power in parallel with the photovoltaic module is generally carried out using electrolytic capacitors of high values. Moreover, the two stages of this topology must be sized for a power equal to twice the nominal power. Finally, another drawback of this topology is the low power factor due to the existence of a zero-crossing distortion.

\subsection{Flyback inverter with high power decoupling}

This topology consists of the flyback inverter with a buck-boost converter [43]. The circuit of this topology is given in Figure 13.

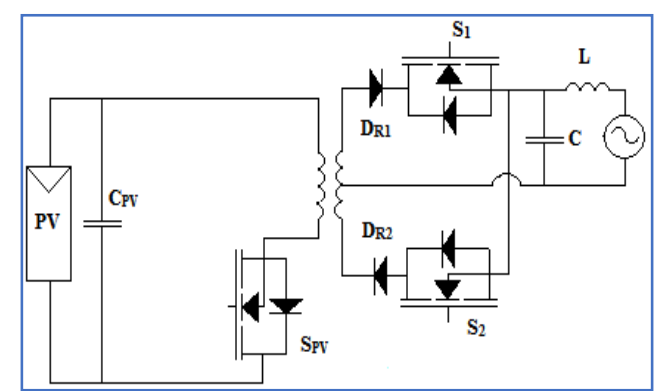

Figure 12. Flyback mono-transistor inverter

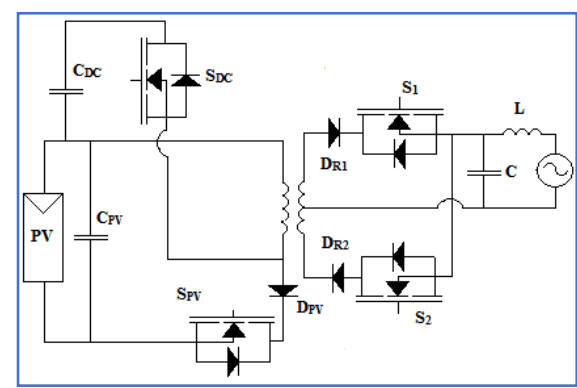

Figure 13. Flyback inverter with high power decoupling 
The topology is a modified version of the one presented in Figure 12 in order to avoid the use of high value electrolytic capacitors. Indeed, the decoupling capacitor is eliminated using a buck-boost converter. This is a topology where the transistor $S_{p v}$, the diode $D_{p v}$, the primary winding of the transformer, the freewheeling diode of the transistor $\mathrm{S}_{\mathrm{DC}}$ and the capacitor $\mathrm{C}_{\mathrm{DC}}$ form the buck-boost converter operating in the discontinuous conduction mode.

Each cycle begins with the conduction of the transistor $S_{\mathrm{PV}}$ which results in a linear increase of the magnetization current. When this current reaches a so-called reference value, the transistor $\mathrm{S}_{\mathrm{PV}}$ is blocked and the energy stored in the magnetization inductance is transferred to the capacitor $\mathrm{C}_{\mathrm{DC}}$. The transistor $\mathrm{S}_{\mathrm{DC}}$ must be active when the current is being discharged to the capacitor which implies the state of zero voltage switching.

In addition, one of the two output transistors is simultaneously activated with the transistor $\mathrm{S}_{\mathrm{DC}}$. Thus, the transistors on the secondary side of the inverter switch at high frequency regime unlike the topology of the Flyback inverter. The magnetization current continues to decrease until reaching a second reference. At this time, the transistor $\mathrm{S}_{\mathrm{DC}}$ will turn $\mathrm{OFF}$ and the energy stored in the inductor is transferred to the secondary side of the transformer and then to the grid. The diode $\mathrm{D}_{\mathrm{PV}}$ is used to eliminate the reverse voltage across the capacitor $\mathrm{C}_{\mathrm{PV}}$ when the energy is being transferred to the secondary side.

\subsection{The modified "SHIMIZU" inverter}

The previous topology shows voltage spikes at the leakage inductance included in the transformer [44]. Such voltage spikes exist between the terminals of the transistor $\mathrm{S}_{\mathrm{DC}}$ during its transition to the OFF state. Also, this topology has been improved by replacing the single-transistor converter with a bi-transistor converter as shown in Figure 14.

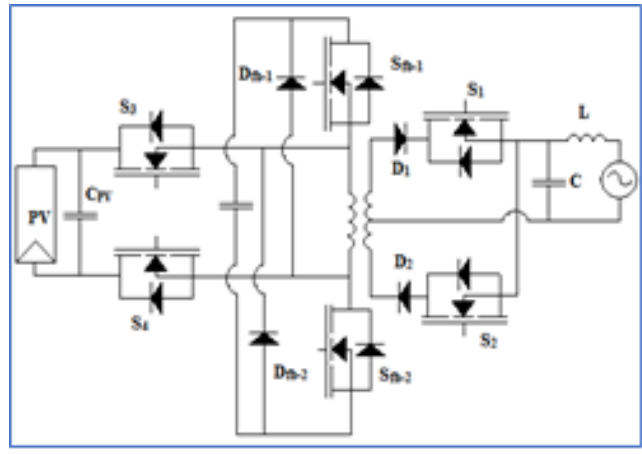

Figure 14. Modified "Shimizu” inverter

Initially, the input energy of the inverter is converted using the boost converter and is saved in the intermediate capacitor. This energy is then converted using the Flyback converter. Finally, the energy stored in the magnetization inductance is returned to the grid through the transformer.

\subsection{The isolated inverter with parallel-parallel configuration}

The inverter made in the parallel-parallel configuration is shown in Figure 15. It delivers a power of the order of 200W [45]. It is an inverter that is designed to operate in the discontinuous conduction mode, DCM. This results in a discontinuous current in one of the inductances $\mathrm{L}_{\mathrm{pv}}$ or $\mathrm{L}$. The advantage of this topology lies in the fact that the discontinuous conduction mode is generally associated with: a) a simple control, b) a reduced size of the inductance $\mathrm{L}_{\mathrm{PV}}$, and c) a current injected into the grid free of $\mathrm{HF}$ ripples/fluctuations.

At the output of the transformer, there are two conversion stages whose outputs are connected in quasi-parallel. One stage is responsible for producing the positive alternation of the current, the second stage is responsible for the negative alternation.

\subsection{The bi-transistor flyback inverter}

This inverter topology is shown in Figure 16. Its output power is around $160 \mathrm{~W}$. The operating principle is detailed in [46]. At the beginning of a period of the grid current, the transistors $S_{1}$ and $S_{4}\left(S_{2}\right.$ and $\mathrm{S}_{3}$ for the negative half-period) are activated. This will generate a current and the energy produced will be saved in the magnetization inductance. When these two transistors are deactivated, the energy will be 
transferred to the secondary side of the transformer and will subsequently be transmitted to the grid through the transistor $\mathrm{S}_{5}$, the freewheeling diode of the transistor $\mathrm{S}_{6}$ and the filter.

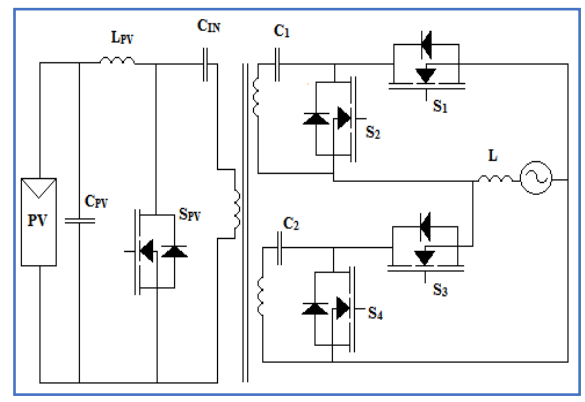

Figure 15. Isolated inverter with parallel-parallel configuration

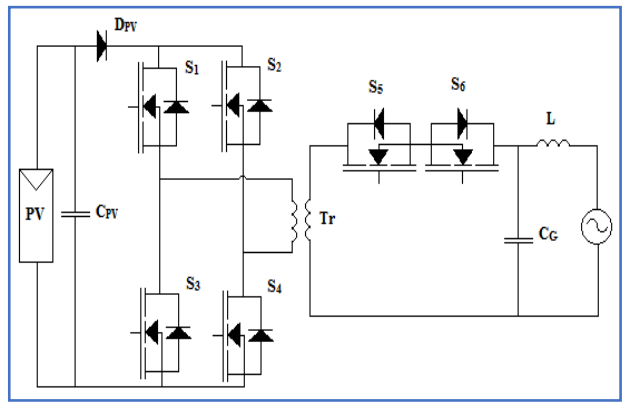

Figure 16. Inverter type flyback bi-transistor

\subsection{Isolated flyback inverter in parallel-series connection}

The topology is shown in Figure 17. It is built around two independent flyback converters [47]. In this case, the grid is connected in series with the outputs of the two converters while the photovoltaic module is connected in parallel with the inputs of the converters. Producing a power of $160 \mathrm{~W}$, the inverter operates in continuous conduction mode, CCM, which results in a more complicated control. It produces an output voltage of $\mathrm{AC}$ type by modulating two sinusoidal voltages shifted by $180^{\circ}$ across the capacitors $\mathrm{C}_{1}$ and $\mathrm{C}_{2}$.

\subsection{Low frequency inverter associated with a flyback converter}

This inverter topology is shown in Figure 18. It is built around a Flyback converter connected to a thyristor-based inverter. It is dedicated to produce a power of about $150 \mathrm{~W}$. In some cases, this power is limited to $100 \mathrm{~W}$. The use of thyristors instead of power transistors can cause some switching problems as the thyristors are current controlled [48].

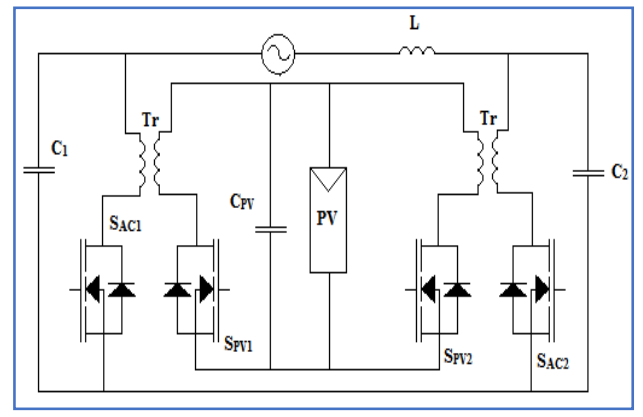

Figure 17. Isolated flyback inverter in parallel-series connection

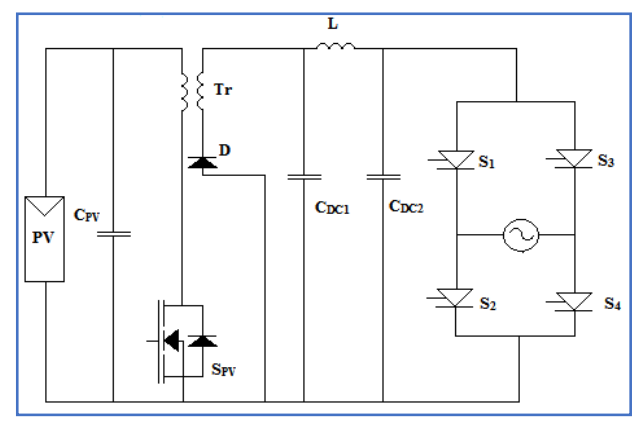

Figure 18. Low frequency inverter associated with a flyback converter

\subsection{Inverter with series resonance converter}

The topology of this inverter associated to a converter is shown in Figure 19. It is built around a series resonance converter connected to a high frequency galvanically isolated inverter. It is designed to produce a power of about $110 \mathrm{~W}$ [49] and can reach $250 \mathrm{~W}$ in some cases [50]. Moreover, the transformer leakage inductance and the capacitor connected in series form a resonance circuit that reduces the switching losses of the inverter.

The DC-DC converter switches at $100 \mathrm{KHz}$ with a duty cycle slightly less than $50 \%$ and it operates with a fixed conversion ratio, which makes it possible to overcome the power decoupling between the photovoltaic module and the grid. The losses within the converter are quite small while those of the transformer are considerable. 
The inverter uses two types of switching frequency: high frequency and low frequency. Indeed, the left arm of the inverter operates at frequencies between 20 and $80 \mathrm{KHz}$ while the right arm switches to $100 \mathrm{~Hz}$. In this case, the switching losses are halved compared to those of the inverters whose two arms switches at high frequencies.

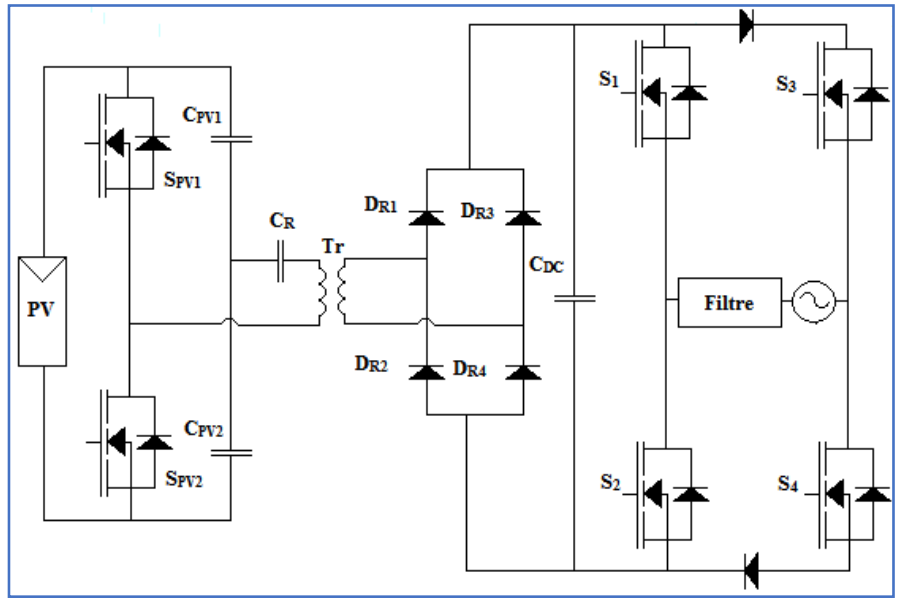

Figure 19. Inverter with series resonance converter

\subsection{H-bridge inverter}

This inverter is whose topology is shown in Figure 20. Made up of two transistor arms and having no transformer, this topology is satisfactory in variable speed drives for AC motors and in UPS. About control strategy, different PWM techniques could be implemented [51].

The H-bridge inverter is characterized by a low efficiency compared to other transformerless topologies due to the use of high frequency PWM control signals. The output voltage of the inverter exhibits significant fluctuations which are at the origin of a relatively large leakage current depending only on the value of the parasitic capacitances $\mathrm{C}_{\mathrm{PV}-\mathrm{G}}$ that exist between the photovoltaic module and the ground. One solution for reducing the leakage current, in the case of bipolar PWM, is to use an LCL filter whose two inductors are located on either side of the load as shown in Figure 21. Such a filter makes it possible to solve the problem of leakage current for the bipolar PWM H-Bridge inverter provided that the two inductors, on either side of the load, are perfectly symmetrical. Although the problem of leakage current is solved, the energy efficiency remains low compared to the transformerless topologies.

The unipolar PWM strategy could also be applied to H-Bridge inverter topology. In this case, the voltage of the inverter takes three different values, namely: $+\mathrm{V}_{\mathrm{IN}}, 0$ and $-\mathrm{V}_{\mathrm{IN}}$. Also, the filter becomes simpler and the fluctuations of the output voltage are reduced. This strategy is characterized by a high efficiency. However, the leakage current is quite high so that the H-Bridge topology cannot be used for transformerless topologies.

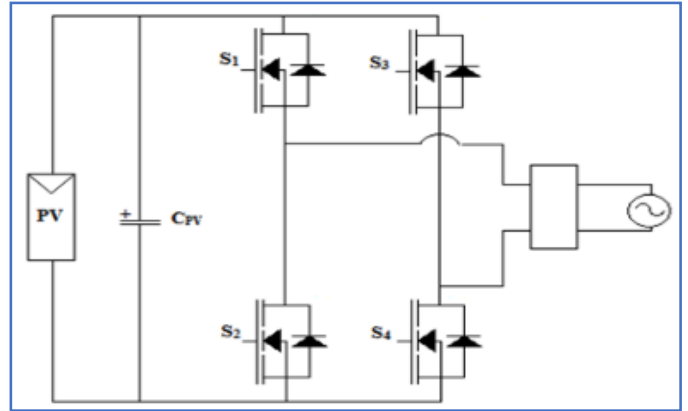

Figure 20. H-Bridge inverter

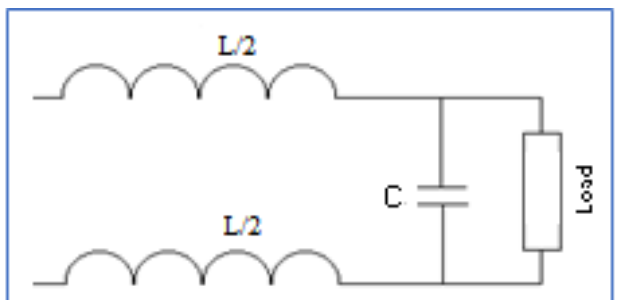

Figure 21. LCL filter configuration for the bipolar PWM H-Bridge inverter 


\subsection{The HERIC inverter topology}

The HERIC topology that was firstly introduced by Sunways is shown in Figure 22 [52]. It is a transformerless inverter topology designed to combine the advantages of bipolar modulation (low leakage current) with those of unipolar modulation (high energy efficiency). The inverter is based on the conventional full bridge topology with two extras transistors interposed at the AC side, as shown in Figure 22.

These transistors are used during the freewheeling time. Indeed, during this phase, one of these transistors is activated while the four transistors of the H-bridge are all OFF and the grid is completely disconnected from the photovoltaic source. the grid current is short-circuited and saved in the load through the transistor $S_{5}$ during the positive alternation and through $S_{6}$ during its negative half-cycle. The fluctuations of the output current are eliminated, and the efficiency of the inverter is significantly improved.

\subsection{The $\mathrm{H5}$ inverter}

SMA has also developed a transformerless inverter topology as shown in Figure 23. The idea is to disconnect the photovoltaic source from the grid during the freewheeling time of the four main transistors of the full bridge topology [53].

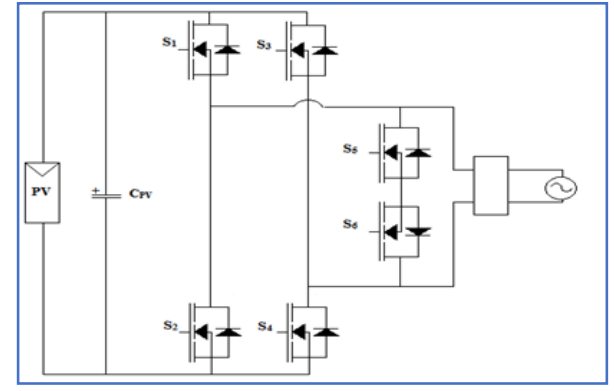

Figure 22. HERIC inverter topology

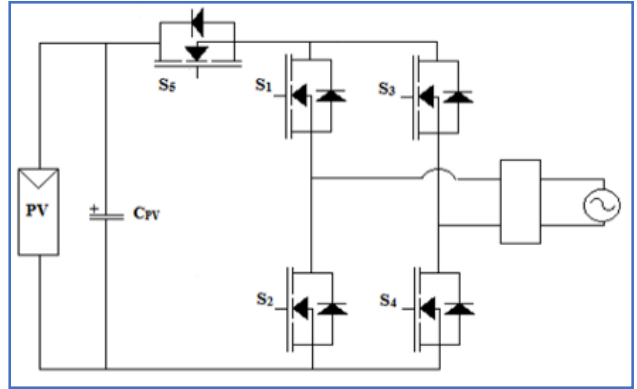

Figure 23. H5 inverter topology

In this case, the modulation used is hybrid. Indeed, the transistors $S_{1}$ and $S_{3}$ switch at the frequency of the grid while $S_{2}$ and $S_{4}$ are switching at high frequencies $\left(S_{1}\right.$ and $S_{4}$ for the positive half period and $S_{2}$ and $\mathrm{S}_{3}$ for the negative half one).

\subsection{Single phase inverter with de decoupling}

By still adopting the same idea of decoupling the inverter from the grid, another topology has been developed in [54] and is shown in Figure 24. The disconnection is carried out using the two extras transistors, $\mathrm{S}_{5}$ and $\mathrm{S}_{6}$, and the two extra diodes, $\mathrm{D}_{1}$ and $\mathrm{D}_{2}$, connected at the DC bus to the input of the inverter.

The output of the inverter is of the three-level type as in the case of the HERIC and H5 inverters. In addition, the level of the leakage current remains within the international standards. This cumulative potential makes this topology a good candidate for structures without transformers.

For this transformerless inverter topology, the modulation is hybrid. Indeed, the two transistors $\mathrm{S}_{5}$ and $S_{6}$ switch at high frequency while the other transistors switch at the grid frequency $\left(S_{1}\right.$ and $S_{4}$ for the positive half periods and $S_{2}$ and $S_{3}$ for the negative half periods).

\subsection{Half bridge inverter}

The inverter based on this topology is built using only two transistors as shown in Figure 25 [55]. For this topology, the two transistors switch at high frequency. As a result, the output of the inverter is of two-level type, which requires larger filtering elements. This topology has low leakage current, which makes it suitable for structures without transformers. However, the major disadvantage is that it requires a DC input voltage equal to twice the input voltages of the other topologies.

Indeed, for a single-phase system, this topology requires a DC voltage of the order of 650V which implies an open circuit voltage of the order of $1000 \mathrm{~V}$; a voltage that is not allowed by the standards setting the open circuit voltage of photovoltaic panels such as the IEC61216 standard. 


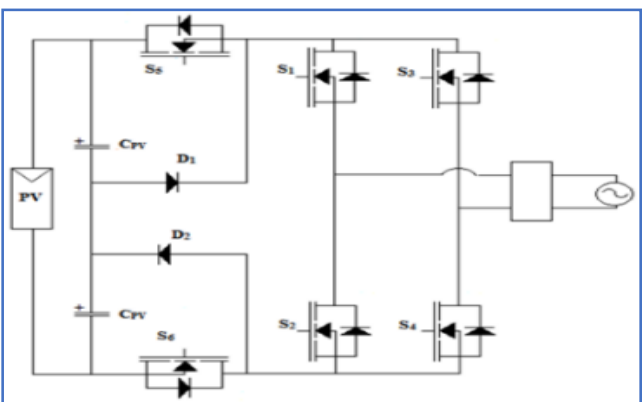

Figure 24. Inverter based on single-phase topology with DC decoupling

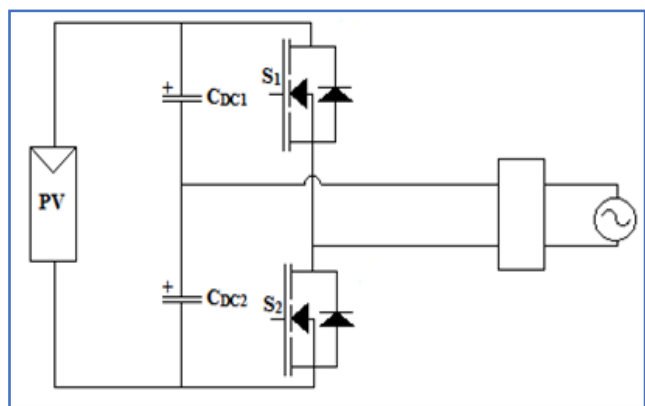

Figure 25. Inverter based on half bridge topology

\subsection{The neutral point clamped inverter topology (NPC)}

The NPC inverter topology is very often used for inverters without transformers. Its structure is shown in Figure 26 [56]-[58]. The phase and the neutral are clamped through two diodes at the mid-point of the two capacitors of the DC bus. The control strategy is hybrid while the transistor $S_{2}$ being active during the positive half-cycle, and the transistor $S_{1}$ is in the switching state. The current flows from the source to the load through the two switches $S_{1}, S_{2}$ and the diode $D_{1}$. During the negative half cycle, the transistor $S_{3}$ is kept in the active state while the transistor $\mathrm{S}_{4}$ is in the switched state.

The inverter based on this topology has some advantages such as the low switching losses rate, a reduced current ripple, an output voltage having three levels which reduces the size of the filter. In addition, the inverter operates with a power factor close to the unit which improves the efficiency of the complete system. However, this topology has certain limitations, particularly in the case of single-phase applications. Among these limitations, it is necessary to distinguish the high level of the DC bus voltage which should be doubled compared to that adopted for the other inverters. Moreover, this topology generates high transient voltages at the transistors $S_{2}$ and $S_{3}$ because, unlike the two transistors $S_{1}$ and $S_{4}$, these two transistors are not connected to the coupling capacitors.

\subsection{Inverter with floatig inductor "Karshny"}

The floating inductance inverter, "Karschny", belongs to the "Sitop Solar" family of Siemens [59][61]. The topology is presented in Figure 27. One can highlight a direct connection between the neutral of the output and the negative terminal of the photovoltaic module. such a connection helps to, a) eliminate the oscillations of the voltage, and b) use thin-film photovoltaic modules.

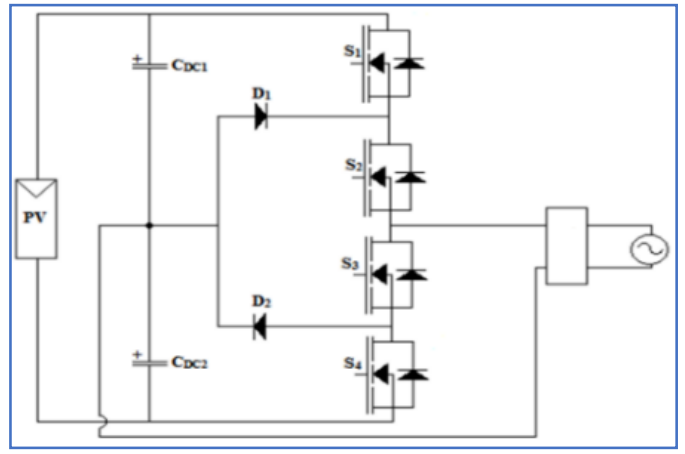

Figure 26. Inverter based on the NPC topology

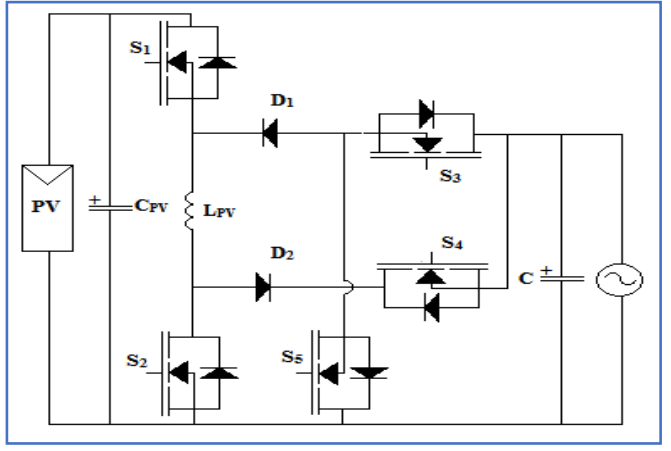

Figure 27. Inverter based on "Karschny" topology

The basic structure of this topology is built around a buck-boost stage with additional transistors to define the polarity of the output quantities. The major disadvantage of this topology lies in the fact that the current passes through several semiconductor components in its path which results in a reduction in efficiency and an increased inverter cost. Table 4 summarizes the differences among between transformerbased inverters and transformer-less inverters discussed in this paper. 
Table 4. Differences between transformer based and transformer-less inverters.

\begin{tabular}{lll}
\hline Inverter & Advantages & Disadvantages \\
\hline Line-frequency transformer based & $\begin{array}{l}\text { Easy design, high reliability, safety due to } \\
\text { galvanic isolation }\end{array}$ & $\begin{array}{l}\text { Low efficiency, high weight, } \\
\text { and volume }\end{array}$ \\
$\begin{array}{l}\text { inverter High-frequency } \\
\text { transformer-based inverter }\end{array}$ & $\begin{array}{l}\text { Easy design, compact, lightweight, high } \\
\text { efficiency, safety due to galvanic } \\
\text { Transformer-less inverter }\end{array}$ & $\begin{array}{l}\text { Complex, costly technology } \\
\text { high efficiency }\end{array}$ \\
\hline
\end{tabular}

\section{CONCLUSION}

Within this paper, a review of photovoltaic conversion chains architecture has been conducted. Two major characteristics have been retained to classify these chains, namely: the galvanic isolation and the number of conversion system stages; characteristics usually localized around the DC-AC inverter. For this reason, a special focus is granted to the different inverter topologies that can be integrated into photovoltaic conversion chains.

Apart from the number of stages, photovoltaic inverters are classified into two groups -inverters with transformers and inverters without transformers. In the first group, the transformer is of high frequency (HF) type and it is located at the DC side, thus making it possible to increase the voltage of the photovoltaic module. A low frequency type transformer is placed at the output side of the inverter to amplify the output voltage to the local standard voltage values of $110 \mathrm{~V}$ or $220 \mathrm{~V}$. In both cases, inverters with HF or LF transformers have been reported to have additional losses of at least $2 \%$. Moreover, transformers are bulky and big in size, especially the LF ones penalizing the compactness of the conversion chain.

The second group includes the inverter topologies without transformer. Indeed, these topologies offer advantages in terms of size, mass and efficiency. However, they suffer from certain shortcomings related to the absence of galvanic isolation. These disadvantages are essentially the existence of a resonance circuit made up of the filter, the photovoltaic module(s) and the parasitic capacitances that appear between the photovoltaic module and the ground. This resonance circuit generates a leakage current that can sometimes exceed certain standards set by international institutions.

As a result, various transformerless inverter topologies with acceptable leakage current level have been developed and presented in the literature. The most famous ones have been presented within this paper. Although these topologies present an acceptable level of performance, some improvements are required. Nonetheless, the transition from centralized structures to other distributed architecture has paved the way to develop new structures where the DC-DC power converter includes multi-string structures or DC optimizers used significantly in residential photovoltaic installations.

\section{REFERENCES}

[1] Yingzi, L., and Yexia, H. "Comparison and selection of solar radiation data for photovoltaic power generation project," J. Electr. Eng. Technol., vol. 14, no. 11, pp. 685-692, 2019, DOI: 10.1007/s42835-019-00110-3.

[2] Fondation D'entreprise Alcen Pour la Connaissance des Énergies (2017). Available at: https://www.connaissancedesenergies.org/fiche-pedagogique/solaire-photovoltaique.

[3] https://www.hahasmart.com/blog/2772/the-history-of-solar-inverters], accessed September 30, 2020.

[4] Guerrero, J.M., and Xue, Y., "Smart inverters for utility and industry applications," PCIM Proceedings, Europe 2015 International Exhibition and Conference for Power Electronics, Intelligent Motion, Renewable, Energy and Energy Management, Nuremberg, Germany, 19-20 May 2015, pp. 277-284.

[5] REVE, solar PV Global Capacity and Annual Additions, 2009-2019 https://www.evwind.es/2020/07/05/in-2019the-solar-pv-market-increased-an-estimated-12-to-around-115-gw/75561, accessed October 1, 2020

[6] Wawrzyniak, C., Moeyaert, V., and Vallee, F, "Impact of the control-command process in a photovoltaic conversion chain on the power line channel transfer function in the narrowband PLC frequency range," CIRED - Open Access Proceedings Journal, vol. 2017, no. 1, pp. 719-723, DOI:10.1049/oap-cired.2017.0078.

[7] Ahmad, Z., and Singh, S. N., "Comparative analysis of single phase transformerless inverter topologies for grid connected PV system," Solar Energy, vol. 149, pp. 245-271, 2017, DOI: 10.1016/j.solener.2017.03.080.

[8] Khan, M. N. H., Forouzesh, M., Siwakoti, Y. P., Li, L., Kerekes, T., and Blaabjerg, F, "A classification of singlephase transformerless inverter topologies for photovoltaic applications," 2018 IEEE Region Ten Symposium (Tensymp), DOI: 10.1109/tenconspring.2018.8692013.

[9] Ahmad, Z., and Singh, S. N., "Single phase transformerless inverter topology with reduced leakage current for grid connected photovoltaic system," Electric Power Systems Research, vol. 154, pp. 193-203, 2018, DOI: 10.1016/j.epsr.2017.08.031.

[10] Ahmad, Z., and Singh, S. N., "Improved modulation strategy for single phase grid connected transformerless PV inverter topologies with reactive power generation capability," Solar Energy, vol. 163, pp. 356-375. DOI: 10.1016/j.solener.2018.01.039. 
[11] Ruchira, Sao, A., Patel, R. N., and Sinha, S. K., "GUI supported experimental investigation of central inverter and microinverter integrated with $1 \mathrm{~kW}$ PV system," 2018 3rd International Conference and Workshops on Recent Advances and Innovations in Engineering (ICRAIE), DOI:10.1109/icraie.2018.8710422.

[12] Muller, N., Kouro, S., Renaudineau, H., and Wheeler, P., "Energy storage system for global maximum power point tracking on central inverter PV plants," 2016 IEEE 2nd Annual Southern Power Electronics Conference (SPEC), 2016, DOI: $10.1109 /$ spec.2016.7846164.

[13] Tariq, M. S., Butt, S. A., and Khan, H. A., "Impact of module and inverter failures on the performance of central-, string-, and micro-inverter PV systems," Microelectronics Reliability, vol. 88-90, pp. 1042-1046. DOI: 10.1016/j.microrel.2018.06.096.

[14] Birane, M., Larbes, C., and Cheknane, A., "Comparative study and performance evaluation of central and distributed topologies of photovoltaic system," International Journal of Hydrogen Energy, vol. 42, no. 13, pp. 8703-8711, DOI: 10.1016/j.ijhydene.2016.09.192.

[15] A. Mohammed, "Renewable energy for sustainable rural development: significant potential synergies, but mostly unrealized," European Court of Auditors, 2018.

[16] PL Chapman, ZS Judkins, and J Marshall (2019) - US Patent US10498253B2.

[17] Zapata, J. W., Kouro, S., and Perez, M. A., "Partial power converter for a two-stage photovoltaic cascaded string inverter," IECON 2017 - 43rd Annual Conference of the IEEE Industrial Electronics Society, 2017, DOI: 10.1109/iecon.2017.8217372.

[18] Roy, J., and Ayyanar, R., "A single-phase transformer-less string inverter with integrated magnetics and active power decoupling," 2017 IEEE Applied Power Electronics Conference and Exposition (APEC), 2017, DOI: 10.1109/apec.2017.7931215.

[19] Sangwongwanich, A., Yang, Y., Blaabjerg, F., and Sera, D., "Delta power control strategy for multistring gridconnected PV inverters," IEEE Transactions on Industry Applications, vol. 53, no. 4, pp. 3862-3870, 2017, DOI: 10.1109/tia.2017.2681044.

[20] Sangwongwanich, A., Yang, Y., Blaabjerg, F., and Sera, D., "Delta power control strategy for multi-string gridconnected PV inverters," 2016 IEEE Energy Conversion Congress and Exposition (ECCE), 2016, DOI: 10.1109/ecce.2016.7854998.

[21] Khan, O., Xiao, W., and Moursi, M. S. E., "A new PV system configuration based on submodule integrated converters," IEEE Transactions on Power Electronics, vol. 32, no. 5, pp. 3278-3284, 2017. DOI: 10.1109/tpel.2016.2633564.

[22] Dube, A., Rizwan, M., and Jamil, M., "Analysis of single-phase grid connected PV system to identify efficient system configuration," 2016 Second International Innovative Applications of Computational Intelligence on Power, Energy and Controls with Their Impact on Humanity (CIPECH), 2016, DOI: 10.1109/cipech.2016.7918761.

[23] Rallabandi, V., Akeyo, O. M., and Ionel, D. M., "Modeling of a multi-megawatt grid connected PV system with integrated batteries," 2016 IEEE International Conference on Renewable Energy Research and Applications (ICRERA), 2016, DOI:10.1109/icrera.2016.7884512.

[24] Hirota, A., Mekhilef, S., \& Nakaoka, M., "A lower switching noise two-legs three-phase inverter applying new type modulation scheme," 2016 IEEE Region 10 Conference (TENCON), 2016, DOI: 10.1109/tencon.2016.7847963.

[25] Meshcheryakov, V. N., Voekov, V. N., and Golovachev, I. V., "Vector control system of PMSM based on selfcommutated voltage inverter with relay controlled IGBT switch in DC link," 2018 17th International Ural Conference on AC Electric Drives (ACED), 2018, DOI:10.1109/aced.2018.8341703.

[26] Xing, L., and Wei, Q., "Series-connected current source inverters with less switches," IEEE Transactions on Power Electronics, vol. 35, no. 6, June 2020, DOI:10.1109/tpel.2019.2951794.

[27] Xia, Y., and Ayyanar, R., "Comprehensive comparison of THD and common mode leakage current of bipolar, unipolar and hybrid modulation schemes for single phase grid connected full bridge inverters," 2017 IEEE Applied Power Electronics Conference and Exposition (APEC), 2017. DOI:10.1109/apec.2017.7930777.

[28] Ramesh Babu, A., Raghavendiran, T. A., Sivachidambaranathan, V., and Barnabas Paul Glady, J., "Novel cascaded H-bridge sub-multilevel inverter with reduced switches towards low total harmonic distortion for photovoltaic application," International Journal of Ambient Energy, vol. 39, no. 9, pp. 1-13, 2017, DOI: 10.1080/01430750.2016.1269683.

[29] Wang, Z., Li, Q., Tang, Y., Liu, S., and Dai, S., "Comparison of harmonic limits and evaluation of the international standards," MATEC Web of Conferences, vol. 277, 03009, 2019, DOI: 10.1051/matecconf/201927703009.

[30] M.P. Kasmier kowski, R. Krishnan, and F. blaabjerg, "Control in power electronics selected problems," 2002, Elsevier.

[31] "Danish standards foundation DS/HD 60364-7-712 (SIK) low-voltage electrical installations - Part 7-712, Requirements for special installations or locations - Photovoltaic (PV) systems," 2016. Available at: https://standards.globalspec.com/std/10073929/ds-hd-60364-7-712-sik.

[32] "IEEE standard conformance test procedures for equipment interconnecting distributed resources with electric power systems," in IEEE Std 1547.1-2005, 1 July 2005, pp.1-62, DOI: 10.1109/IEEESTD.2005.96289.

[33] "IEEE recommended practice for utility interface of photovoltaic (PV) systems," in IEEE Std 929-2000, 2000, DOI: 10.1109/IEEESTD.2000.91304.

[34] IEC 61727 photovoltaic (PV) systems - Characteristics of the utility interface (2004). Available at: https://standards.globalspec.com/std/365170/iec-61727.

[35] BS EN IEC 61000-3-2:2019 electromagnetic compatibility (EMC), Limits - limits for harmonic current emissions (equipment input current up to and including 16 A per phase) (2019), British Standards Institution. 
[36] Rahman, M. A., Islam, M. R., Mahfuz-Ur-Rahman, A. M., Muttaqi, K. M., and Sutanto, D., "Investigation of the effects of DC current injected by transformer-less pv inverters on distribution transformers," IEEE Transactions on Applied Superconductivity, vol. 29, no. 2, pp. 1-4, 2019, DOI: 10.1109/tasc.2019.2895580.

[37] Long, B., Huang, L., Sun, H., Chen, Y., Victor, F., and Chong, K. T., "An intelligent dc current minimization method for transformerless grid-connected photovoltaic inverters," ISA Transactions, vol. 88, pp. 268-279, 2018, DOI: 10.1016/j.isatra.2018.12.005.

[38] Fang, W., Wu, D., Huang, L., Long, B., and Chen, Y., "Component minimization of transformerless LCL-type grid-connected inverter with virtual capacitors," 2019 Chinese Control Conference (CCC), DOI: 10.23919/chicc.2019.8865205.

[39] Arab Ansari, S., \& Moghani, J., "A novel soft switching flyback inverter for photovoltaic AC module applications," IET Renewable Power Generation, vol. 13, no. 13, 2019, DOI: 10.1049/iet-rpg.2019.0365.

[40] Arab Ansari, S., Moghani, J. S., and Mohammadi, M., "Analysis and implementation of a new zero current switching flyback inverter," International Journal of Circuit Theory and Applications, vol. 47, no. 4, 2018, DOI: 10.1002/cta.2577.

[41] Ronilaya, F., Kurniawan, S. B., Hidayat, M. N., Rohadi, E., Sutjipto, R., and Siradjuddin, I., "A power sharing loop control method for input-series output-parallel flyback-type micro-inverter using droop method," 2019 International Conference on Information and Communications Technology (ICOIACT), DOI: 10.1109/icoiact46704.2019.8938411.

[42] Chen, C., Li, J., Gao, S., \& Ma, Y., Design of Staggered Fly-back Single-phase Photovoltaic Grid-connected Micro-inverters. 2019 IEEE 3rd Information Technology, Networking, Electronic and Automation Control Conference (ITNEC), 2019, DOI:10.1109/itnec.2019.8729402.

[43] Kabalci, E., Boyar, A., \& Metin, N. A. "Design and Analysis of a Flyback Micro Inverter with H5 Inverter," 2019 1st Global Power, Energy and Communication Conference (GPECOM), 2019, DOI: 10.1109/gpecom.2019.8778530.

[44] Ronilaya, F., Siradjuddin, I., \& Wibowo, S. E., "An optimal power flow control method for PV systems with single phase Shimizu inverter," 2017 International Seminar on Intelligent Technology and Its Applications (ISITIA), 2017, DOI:10.1109/isitia.2017.8124058.

[45] Chaudhary, S., \& Singh, S. N., "Single Phase Grid Interactive Solar Photovoltaic Inverters: A Review," 2018 National Power Engineering Conference (NPEC), 2018, DOI:10.1109/npec.2018.8476767.

[46] Ansari, S. A., Hosseinian, S. hossei., \& Moghani, J. S., "Low-voltage ride-through capability of flyback inverter under BCM operation for AC module applications," 2017 Smart Grid Conference (SGC), 2017, DOI:10.1109/sgc.2017.8308866.

[47] Sher, H. A., Addoweesh, K. E., \& Al-Haddad, K., "An Efficient and Cost-Effective Hybrid MPPT Method for a Photovoltaic Flyback Microinverter," IEEE Transactions on Sustainable Energy, vol. 9, no. 3, pp. 1137-1144, 2018, DOI:10.1109/tste.2017.2771439.

[48] Kamble, S. V., \& Kumar, P., "An improved interleaved high power flyback inverter for photovoltaic application," 2017 International Conference on Computation of Power, Energy Information and Commuincation (ICCPEIC), 2017, DOI:10.1109/iccpeic.2017.8290484.

[49] Yeh, C.-S., Chen, C.-W., Lee, M., \& Lai, J.-S. "A Hybrid Modulation Method for Single-Stage Soft-Switching Inverter Based on Series Resonant Converter," IEEE Transactions on Power Electronics, 1-1, 2019 DOI: 10.1109/tpel.2019.2948122.

[50] Alhamroun, I., Salem, M., Jusoh, A., Idris, N. R. N., Ismail, B., \& Albatsh, F. M. "Comparison of two and four switches inverter feeding series resonant converter," 2017 IEEE Conference on Energy Conversion (CENCON), 2017, DOI:10.1109/cencon.2017.8262508.

[51] Ray, S., Gupta, N., \& Gupta, R. A., "A Comprehensive Review on Cascaded H-bridge Inverter-Based Large-Scale Grid-Connected Photovoltaic," IETE Technical Review, vol. 34, no. 5, pp. 463-477, 2016, DOI: $10.1080 / 02564602.2016 .1202792$

[52] Orfanoudakis, G. I., Sharkh, S. M., Koutroulis, E., \& Yuratich, M. A. "Single-phase transformerless PV inverter topology with AC bypass and mid-DC-link voltage clamping," 2017 19th European Conference on Power Electronics and Applications (EPE'17 ECCE Europe), 2017, DOI:10.23919/epe17ecceeurope.2017.8098973.

[53] Tarek Selmi and Maher Rezgui, "A novel DC-AC inverter topology to eliminate leakage current," International Journal of Power Electronics and Drive System (IJPEDS), vol. 9, no. 4, pp. 1733-1744, 2018, DOI: 10.11591/ijpeds.v9n4.pp1733-1744.

[54] Tarak Salmi, Mounir Bouzguenda, Adel Gastli and Ahmed Masmoudi, "A novel transformerless inverter topology without zero-crossing distortion,” International Journal of Renewable Energy Research, vol. 2, no. 1, pp. 140-146, 2012.

[55] Babaei, E., and Shokati Asl, E., "A new topology for Z-source half-bridge inverter with low voltage stress on capacitors," Electric Power Systems Research, vol. 140, pp. 722-734, 2016, DOI: 10.1016/j.epsr.2016.04.010.

[56] Viju Nair, R., Chattopadhyay, R., Parashar, S., Bhattacharya, S., and Gopakumar, K., "Cascaded active neutral point clamped and flying capacitor inverter topology for induction motor drives applications," 2018 IEEE Energy Conversion Congress and Exposition (ECCE), 2018, DOI: 10.1109/ecce.2018.8557745. 


\section{BIOGRAPHIES OF AUTHORS}

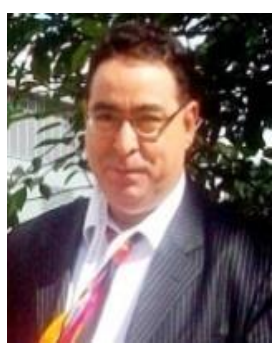

Dr. Mounir Bouzguenda (PhD Virginia Tech 1992) is an Associate Professor, Electrical Engineering at King Faisal University, Al Hasa, Saudi Arabia. Dr. Bouzguenda received his BS and MSc degrees in Electrical Engineering from Pennsylvania S tate University and Virginia Tech in 1985 and 1988, respectively. Dr. Mounir taught in Oman, Tunisia, US and now in KSA. He also worked as a consultant with Standard Technologies Institute, Maryland and the Temple Group, Washington DC and Computer Engineering Services, Tunisia. In 2012, Dr. Mounir joined King Faisal University-KSA as an Associate Professor and he has been teaching since then. His research interests include smart grid, renewable energy systems, power systems and power electronics. He has authored and co-authored many technical papers in these areas. Email: mbuzganda@kfu.edu.s

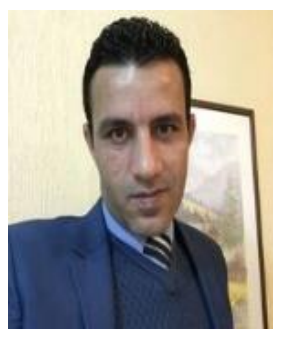

Tarek Selmi received his B.Sc. degree from Tunis University of Sciences in 2002, his M.Sc. degree from Monastir University of Sciences in 2007 and the $\mathrm{PhD}$ degree from the National Engineering School of Sfax, Tunisia in 2013. He joined the Tunisian Ministry of Higher Education in 2002 and the Oman Ministry of Manpower in 2008 where he worked as a power electronics instructor and a coordinator of the Electronics Department for 3 years. Then, he worked as an Assistant professor at the Australian College of Kuwait for three years and served as a deputy head of the electrical engineering department. Dr. Tarek worked as an assistant professor in Electrical Engineering at Sohar University, Oman. Currently he is an Assistant Professor at High Institute of Applied Sciences and Technology, University of Kairouan. Dr Tarek has published more than 25 journal and conference papers in modeling power semiconductor devices based on silicon carbide (SiC), power electronic systems, renewable energy systems especially solar photovoltaics, microcontrollers, Mechatronic systems, and Programmable logic controllers. Email: tarek.selmi@issatkr.u-kairouan.tn 